\title{
BIORREMEDIAÇÃO DE EFLUENTES POR MEIO DA APLICAÇÃO DE MICROALGAS - UMA REVISÃO
}

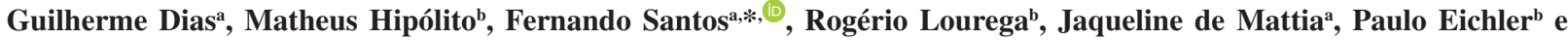 \\ Jonathan Alves ${ }^{\mathrm{a}}$ \\ a'Universidade Estadual do Rio Grande do Sul, 93340-000 Novo Hamburgo - RS, Brasil \\ bPontifícia Universidade Católica do Rio Grande do Sul, 90619-900 Porto Alegre - RS, Brasil
}

Recebido em 29/03/2019; aceito em 18/06/2019; publicado na web em 01/08/2019

\begin{abstract}
BIORREMEDIATION OF INDUSTRIAL EFFLUENT USING MICROALGAE. National industrial effluent remediation strategies are largely outdated, which makes these processes costly and at the same time inefficient. Among the most worrying compounds are heavy metals, which have bioaccumulative and toxic characteristics to living beings. In addition to these, high nutrient loads constitute a huge environmental problem, since the devastation promoted by eutrophic niches is capable of disrupting complex food chains. This paper presents a bibliographical review of the current researches that are applying biomass from microalgae in effluent bioremediation, both domestic and industrial (mainly the latter, since its pollution potential is abruptly greater). Such strategy is interesting since the diversity of these microorganisms is abundant, propitiating the application of them in various conditions. Another point to be taken into consideration is the fact that many species of microalgae produce large amounts of lipids, many of which have potential application in the production of biodiesel.
\end{abstract}

Keywords: biosorption; biomass; heavy metals.

\section{INTRODUÇÃO}

Em decorrência da grande expansão populacional, advinda principalmente da revolução industrial que instaurou uma nova forma de organização social à população humana, inúmeros problemas ambientais foram se somando ao decorrer das décadas. ${ }^{1}$ Dentre esses problemas, a poluição de efluentes industriais com metais pesados merece um destaque especial, uma vez que grande quantidade destes componentes apresentam características biocumulativas, sendo tóxicas e causando inúmeros danos para seres humanos e todo o meio ambiente. ${ }^{2}$

Os metais, de uma forma geral, assim como seus compostos, exibem certo grau de toxicidade característico, sendo tal ação relativa à capacidade inerente que uma espécie possui para efetivar efeitos negativos sobre os organismos com quem entra em contato. Os metais se encontram e distribuem de forma natural no meio ambiente, sendo a lixiviação uma forma relevante para a dispersão natural dos metais pelo meio. Entretanto, a carga antropogênica já contribui de forma excedente quando comparada com as fontes naturais. As principais vias de contribuição humana são: aplicação de pesticidas e fertilizantes, mineração e lançamento de efluentes industriais sem tratamento. É importante destacar que a toxicidade está ligada diretamente com a quantidade de metal disponível e também ao tempo de exposição, sendo que os organismos vivos necessitam de pequenas quantidades de alguns metais para a funcionalidade normal de suas funções vitais. ${ }^{2,3}$

Dentre os metais pesados, pode-se citar o (As), $(\mathrm{Cd}),(\mathrm{Pb}),(\mathrm{Cr})$, (Mn) e (Hg) como os mais preocupantes, principalmente por estarem presentes em processos antropogênicos, o que alavanca sua disposição no meio ambiente. No Brasil, o Conselho Nacional de Meio Ambiente (CONAMA), por meio da Resolução N430, estabelece à quantidade máxima permitida desses metais que podem ser encontrados em determinado efluente. ${ }^{4}$

Tanto a CONAMA, no Brasil, quanto a Environmental Protection Agency (EPA), nos Estados Unidos, são órgãos de proteção ambiental

*e-mail: fernandoasantos7@gmail.com que, em conjunto com o crescente interesse da comunidade acadêmica, estimularam o crescimento de pesquisas envolvendo redução de poluentes em diversas áreas ambientais. ${ }^{5}$

Em relação ao saneamento básico, apesar de existirem parâmetros e diretrizes para a gestão do lançamento de efluentes, do próprio CONAMA, o país enfrenta graves problemas em todo território nacional, sendo que para o lançamento de efluentes industriais a situação é muito semelhante. Isso decorre, principalmente, por falta de fiscalização dos órgãos públicos, responsáveis por tal degradação. ${ }^{6}$ Segundo dados do Trata Brasil de 2018, cerca de 2,4 bilhões de pessoas no mundo não possuem sistema de saneamento adequado e 270 mil crianças morrem, a cada ano, ainda durante o primeiro mês de vida, em decorrência da dificuldade em acesso à água tratada e saneamento básico. Dados alarmantes que poderiam ser corrigidos com a difusão global de medidas remediativas eficientes.

Além da deposição de metais pesados, o despejo de efluentes industriais, domésticos e também de fertilizantes em rios e lagos, propicia o fenômeno de eutrofização, caracterizado pelo crescimento descomedido de organismos autotróficos. Após esse crescimento, ocorre a decomposição da biomassa, que acaba por promover a deterioração de todo o ecossistema aquático, principalmente pela diminuição do oxigênio dissolvido, fator estritamente ligado com o crescimento de organismos decompositores anaeróbios sobre a biomassa. ${ }^{7}$

Devido a todos os problemas causados, medidas de tratamento são indispensáveis. ${ }^{8}$ Os principais motivos da ineficiência dos tratamentos estão centrados no elevado preço nos métodos convencionais, que muitas vezes são incapazes de remover concentrações diminutas de metais pesados e da carga de nutrientes, além da fiscalização muitas vezes precária em âmbito nacional, o que pode ser encarado como estímulo para a banalização de medidas remediativas. ${ }^{6}$

Por tais motivos, o interesse em aplicar uma biomassa alternativa em processos de biorremediação é um viés promissor, uma vez que além de poderem efetivar a remoção de metais pesados e nutrientes, também podem, posteriormente, entrar em processos de biorrefinaria, o que alavanca seu potencial econômico. As microalgas são o interesse da presente revisão, constituindo um grupo de microrganismos cuja eficiência fotossintética é largamente maior quando comparado aos 
vegetais superiores, além de serem capazes de utilizar tanto carbono orgânico quanto inorgânico. ${ }^{9}$ Além disso, produzem grandes quantidades de proteínas, óleos e demais compostos de interesse, sendo que no contexto de biorremediação, muitas de tais substâncias estão inseridas nos processos de biossorção. ${ }^{10}$

\section{MICROALGAS}

O termo microalgas não possui valor taxonômico, sendo que comumente é referido a grupos de microrganismos algais cuja composição celular apresenta pigmentos fotossintéticos sendo capazes de realizar fotossíntese oxigênica. Sendo assim, as microalgas compõem um grupo bastante diversificado de organismos que, em sua grande maioria, são microscópicos e aquáticos, englobando tanto espécies eucarióticas quanto procarióticas. ${ }^{11}$

Constata-se que são microrganismos que, devido à estrutura relativamente simples das células, são passíveis de serem inseridos em aplicações em bioenergia, sendo o não comprometimento de terras utilizadas para produção de alimentos um grande ponto positivo. ${ }^{12}$

Atualmente, grande atenção está sendo dada a esse grupo de microrganismos frente a aplicação dos mesmos na obtenção de biocombustíveis, principalmente biodiesel, uma vez que, dependendo da espécie, é possível obter até 100 mil litros de óleo por hectare (Tabela 1), ${ }^{13}$ um valor expressivo quando comparado ao óleo de dendê, caracterizada como uma das plantas com maior produção de óleo, cuja média de 4-6 t/ha/ano é obtida. ${ }^{14}$

As microalgas, assim como plantas e animais, são capazes de biossintetizar triglicerídeos como forma de armazenamento energético, sendo o L-a-fosfoglicerol e acetil-coA os principais primers aplicados na biossíntese de triglicerídeos, cujos mecanismos de síntese podem ser visualizados na Figura $1 .^{15}$

Os triglicerídeos oriundos de microalgas podem ser inseridos na transesterificação com álcoois de cadeia curta, na presença de catalisadores básicos ou ácidos, como esquematizado na Figura 2.
Tabela 1. Teor de óleo e produtividade de diversas oleaginosas ${ }^{13,14}$

\begin{tabular}{ccc}
\hline Oleaginosa & Teor de óleo $(\% \mathrm{~m})$ & $\begin{array}{c}\text { Prod. de Óleo } \\
\left(\mathrm{kg} \mathrm{ha}^{-1} \mathrm{ano}^{-1}\right)\end{array}$ \\
\hline Microalga & 20 & 100.000 \\
Soja & 18 & 396 \\
Dendê & 20 & 4000 \\
Amendoim & 39 & 702 \\
\hline
\end{tabular}

O metanol é o álcool mais utilizado na obtenção de biodiesel, tendo o porém de ser obtido por meio de fontes fósseis. Para um biodiesel completamente renovável, o uso de etanol deve ser feito, mas esse apresenta algumas desvantagens em comparação ao metanol, como a lentidão e maior complexidade no processo. ${ }^{16}$

O crescimento microalgal, com a consequente produção de óleo, pode ser muito bem associada com estações de tratamento de esgotos (ETE), sendo capazes de realizar um papel muito efetivo em relação a remoção de nutrientes, que as microalgas utilizam para seu crescimento e propagação, gerando ao mesmo tempo compostos que podem ser inseridos em inúmeros processos. ${ }^{17}$

Levando em consideração apenas a produção de óleo pelas microalgas, a Tabela 2 retorna as principais vantagens e desvantagens já constatadas.

Dentre os compostos produzidos pelas microalgas, os ácidos graxos são alvo de uma grande gama de estudos, principalmente em função da aplicação dos mesmos na produção de biodiesel, resultante do fato das grandes quantidades de lipídeos que algumas espécies são capazes de produzir, como pode ser verificado na Tabela 3. Esses microrganismos fotossintéticos sintetizam ácidos graxos por meio de fontes de carbono (como $\mathrm{CO}_{2}$ ) ou diretamente de fontes orgânicas como glicose ou acetato. ${ }^{18}$

Devido à presença de compostos com efeitos nutracêuticos, as microalgas também vêm recebendo atenção das indústrias alimentícias, uma vez que o enriquecimento nutricional de inúmeros alimentos

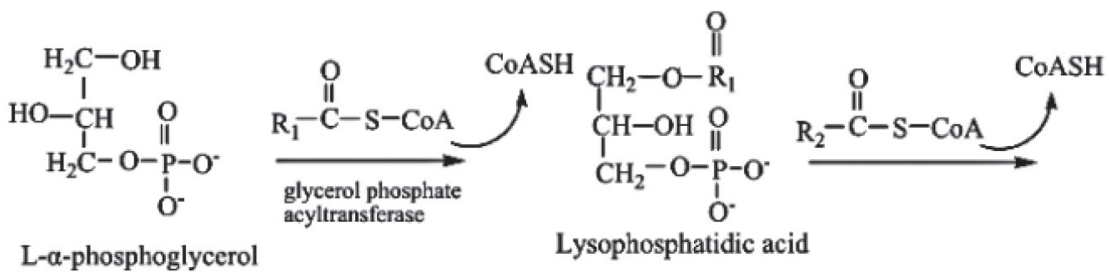<smiles>[R]C(=O)OCC(COC([R])=O)(COP(=O)([O-])[O-])OC([R])=O</smiles>

phosphatidic acid

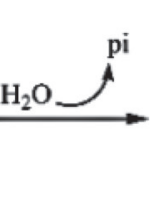<smiles>[R]C(=O)OCC(CO)OC([R])=O</smiles><smiles>[R]C(=O)SCCCC(=O)O</smiles>

Diglyceride<smiles>[R]C(=O)OCC(COC([R])=O)OC([R])=O</smiles>

Triglyceride

Figura 1. Biossíntese de triglicerídeos em microalgas. Adaptada da ref. 15<smiles>[R]C(=O)OCC(COC([R])=O)OC([R2])=O</smiles><smiles></smiles>

Figura 2. Processo de transesterificação de triglicerídeos para obtenção de biodiesel. Adaptada da ref. 16 
Tabela 2. Vantagens e desvantagens verificadas na produção de óleo por microalgas. Adaptado da ref. 15

\begin{tabular}{ll}
\hline Vantagens & Desvantagens \\
\hline $\begin{array}{l}\text { 1. Composição dos ácidos graxos } \\
\text { semelhante a dos óleos vegetais }\end{array}$ & $\begin{array}{l}\text { 1. O custo de cultivo é maior quan- } \\
\text { do comparado com óleos oriundos } \\
\text { de culturas comuns }\end{array}$ \\
$\begin{array}{l}\text { 2. Dependendo da espécie e das } \\
\text { condições de cultivo, a quantidade }\end{array}$ & $\begin{array}{l}\text { 2. Necessidade de operações uni- } \\
\text { tárias para romper a parede celular }\end{array}$ \\
peso poode atingir até 85\% do & para obtenção do óleo \\
$\begin{array}{l}\text { 3. Meios de cultivo relativamente } \\
\text { simples }\end{array}$ & $\begin{array}{l}\text { 3. Facilidade em ocorrer contami- } \\
\text { naçes }\end{array}$ \\
\hline
\end{tabular}

pode ser feito por meio do uso de tais microrganismos, fazendo com que extratos de biomassa de microalgas ganhem cada vez mais espaço no mercado, inclusive, podendo ser facilmente inseridas no contexto de alimentos orgânicos, uma vez que não necessitam de agrotóxicos para atingirem seus elevados índices de produção. ${ }^{10}$

Um dos maiores problemas enfrentados no cultivo de microalgas para obtenção de óleo é resultante do fato de que um dos métodos mais aplicados é o de lagoa aberta, que acaba facilitando a ocorrência de contaminações. Além disso, a produção fica estritamente dependente das condições climáticas, o que muitas vezes pode retardar drasticamente o crescimento da biomassa, que necessita de uma temperatura constante para uma produção rentável bem como iluminação adequada. ${ }^{19}$ Além disso, no cultivo de microalgas existe a necessidade de se manter constante outros parâmetros de processo, como $\mathrm{pH}$, concentração dos nutrientes e do $\mathrm{CO}_{2}$. E, após ocorrer a extração dos lipídios, o óleo obtido possui um alto teor de água e ácidos graxos livres, o que impede o uso direto nos processos alcalinos tradicionais quando o foco é a produção de biodiesel. ${ }^{20}$

A principal saída sendo estudada para contornar os problemas encontrados na produção em larga escala de microalgas reside na otimização de fotobiorreatores, que podem ocupar pequenos espaços, serem instalados em regiões desérticas, bem como terem seus fluxos mássicos de entrada e saída completamente automatizados. ${ }^{19}$

\section{EFLUENTES CONTAMINADOS}

A contaminação de cursos d'água por meio de efluentes domésticos e industriais é um grave problema ambiental, uma vez que pode inviabilizar a utilização da água, recurso necessário para a manutenção da vida. Sendo composta por substâncias orgânicas e inorgânicas, a poluição pode ser definida como química, física ou biológica, alterando determinado ciclo biológico. ${ }^{8}$ Quando se trata da poluição de recursos hídricos, o problema atinge grandes contingentes, uma vez que a dispersão dos compostos poluentes pode se dar forma extremamente rápida.

Dentre os compostos contaminantes que podem ser dispersos nos recursos hídricos, os metais são preocupantes, uma vez que não são degradados física ou biologicamente, ciclando, portanto, entre os diversos compartimentos ambientais. ${ }^{8}$

No âmbito industrial, os métodos tradicionalmente utilizados na descontaminação de efluentes são: precipitação química e filtração, oxidação e redução biológica, oxidação e redução química, tratamento eletroquímico, osmose reversa, troca iônica, adsorção e evaporação. As vantagens e desvantagens de cada método estão dispostas na Tabela 4. De uso muito comum, a troca iônica e a adsorção com carvão ativado são eficientes, mas relativamente caras, isso devido aos custos com operação e equipamentos. ${ }^{23}$

Devido aos problemas encontrados nos processos já utilizados, novas formas de operação, bem como novos métodos de tratamento devem ser estudados. Nesse contexto, os biossorventes são muito relevantes, ainda mais quando são derivados resíduos agroindustriais, ou quando os produtos gerados podem ser aplicados em processos de biorrefinaria (como no caso das microalgas ativas). Aumentar o arcabouço de materiais que podem ser aplicados na remediação de efluentes é uma medida importante e necessária, podendo agregar valor à materiais bem como reduzir custos de processo, o que facilitaria e tornaria sua aplicação muito mais ampla. ${ }^{24}$

\section{MECANISMOS DE BIOSSORÇÃO}

A biossorção está centrada no potencial que certos organismos (animais ou vegetais) apresentam em reter compostos presentes em

Tabela 3. \% de óleo (peso seco) obtido por meio de várias espécies de microalgas. Adaptada das refs. 21 e 22

\begin{tabular}{|c|c|c|c|}
\hline Microalga & \% de óleo (peso seco) & Microalga & $\%$ de óleo (peso seco) \\
\hline Ankistrodesmus sp. & $24-31$ & Monallanthus salina & $>20$ \\
\hline Botryococcus braunii & $25-75$ & Monodus subterraneus & 16 \\
\hline Chaetoceros muelleri & 33,6 & Nannochloris sp. & $20-56$ \\
\hline Chaetoceros calcitrans & $15-40$ & Nannochloropsis sp. & $12-53$ \\
\hline Chlorella emersonii & $25-63$ & Nannochloropsis oculata & 30 \\
\hline Chlorella protothecoides & $15-58$ & Neochloris oleoabundans & $35-54$ \\
\hline Chlorella sorokiniana & $19-22$ & Nitzschia sp. & $16-47$ \\
\hline Chlorella vulgaris & $5-58$ & Oocystis pusilla & 11 \\
\hline Chlorella sp. & $10-48$ & Pavlova salina & 31 \\
\hline Chlorella pyrenoidosa & 2 & Pavlova lutheri & 35 \\
\hline Chlorella & $18-57$ & P. tricornutum & $18-57$ \\
\hline Chlorococcum sp & 19,3 & P. cruentum & $9-60$ \\
\hline Crypthecodinium cohnii & $20-51$ & Schizochytrium sp. & $50-77$ \\
\hline Cylindrotheca sp. & $16-37$ & S. obliquus & $11-55$ \\
\hline Dunaliella salina & $6-25$ & S. quadricauda & $2-18$ \\
\hline Dunaliella primolecta & 23 & Scenedesmus sp. & $20-21$ \\
\hline Dunaliella tertiolecta & $17-71$ & Skeletonema $s p$ & $13-32$ \\
\hline Dunaliella sp & $17-67$ & S. costatum & $13-51$ \\
\hline Ellipsoidion $s p$. & 27 & Spirulina maxima & 12 \\
\hline Euglena gracilis & $14-20$ & Spirulina platensis & 11 \\
\hline Haematococcus pluvialis & 25 & T. pseudonana & 21 \\
\hline Isochrysis galbana & $7-40$ & Tetraselmis sueica & $15-23$ \\
\hline Isochrysis $s p$ & $25-33$ & Tetraselmis sp. & $13-15$ \\
\hline
\end{tabular}


Tabela 4. Vantagens e desvantagens de processos de remediação tradicionalmente utilizados. Adaptada da ref. 23

\begin{tabular}{|c|c|c|c|}
\hline Processo & Mecanismos de ação & Vantagens & Desvantagens \\
\hline Precipitação química & $\begin{array}{l}\text { Uma substância solúvel é convertida em } \\
\text { outra insolúvel por reação química ou } \\
\text { por mudanças na composição do solven- } \\
\text { te. Como ocorre na remoção de fosfatos } \\
\text { e outros sais pela adição de coagulantes } \\
\text { contendo ferro e/ou alumínio. }\end{array}$ & $\begin{array}{c}\text { Simples } \\
\text { Baixo custo }\end{array}$ & $\begin{array}{c}\text { Não efetiva para concentrações } \\
\text { elevadas } \\
\text { Difícil separação } \\
\text { Pouco efetiva } \\
\text { Produz lamas }\end{array}$ \\
\hline
\end{tabular}

Redução e/ou oxidação de matéria orgâ-

Oxidação e redução biológica nica por meio da aplicação de consórcio de microrganismos.
Baixo custo

Quando sistemas biológicos são aplicados, a taxa de conversão é lenta e dependente das condições climáticas

Aplicação de oxidantes químicos como $\mathrm{H}_{2} \mathrm{O}_{2}, \mathrm{O}_{3}, \mathrm{Cl}_{2}, \mathrm{ClO}_{2}$ e $\mathrm{KMnO}_{4}$. Utilizado na oxidação e redução de metais, bem como na desinfecção e remoção de Mineralização

Requer agentes químicos

Oxidação e redução química odor da água.

Imposição de uma diferença de potencial e/ou corrente elétrica a um sistema composto de catodo, anodo e eletrólito. Pode promover destruição anódica do cianeto, ao mesmo tempo que promove remoção catódica dos metais pesados.

Tratamento eletroquímico

\begin{tabular}{ll} 
& catódica dos metais pesados. \\
\hline Uma fonte de pressão externa é aplica- \\
da, fazendo com que a água, por meio \\
de uma membrana semipermeável, se \\
encaminhe da solução mais concentrada \\
para a mais diluída.
\end{tabular}

Resinas de troca iônica são aplicadas, podendo liberar íons sódio ou hidrogênio Troca iônica (resinas catiônicas) bem como hidroxila (resinas aniônicas) e apreender cátions e ânions, respectivamente.

Adsorção com carvão ativado, zeólitas, biomassa, resina polimérica, e oxi-hidróxido metálico

\section{Adsorção}

Evaporação

Evaporação

\section{Separação da água dos demais com-} postos presentes na mesma por meio da passagem da água do estado líquido para estado gasoso. Aplicado para altas concentrações
Recuperação do metal Altas pressões necessárias
Custo elevado

estado gasoso.
Efetivo
Recuperação do metal
Sensível a presença de partículas
Resinas de elevado custo

Adsorventes convencionais

Não efetivo para alguns metais soluções aquosas. Esse potencial é conhecido há muito tempo, entretanto, somente nas últimas décadas é que sua aplicabilidade frente a efluentes industriais contaminados vem sendo estudada. ${ }^{25}$

$\mathrm{O}$ termo biossorção é relativo à retenção de metais (e alguns compostos orgânicos) pela biomassa sem o envolvimento de vias metabólicas neste processo, apesar de que isso possa ocorrer quando biomassa viva for utilizada. ${ }^{26}$

Pino $^{29}$ descreve que a biossorção é uma operação que ocorre por meio de mecanismos variados, atuando em conjunto, ou não, com correlação direta ao tipo de metal a ser removido, bem como o organismo utilizado. Como relatado por Boniolo, ${ }^{27}$ o processo torna-se interessante em decorrência de que os biossorventes possuem, principalmente em suas paredes celulares, uma quantidade variável e grande de grupamentos orgânicos como, por exemplo, amidas, aminas, ácidos carboxílicos e fenóis. Tais grupamentos propiciam os seguintes mecanismos: complexação, coordenação, quelação, microprecipitação, adsorção e troca iônica. ${ }^{28}$

Portanto, a biossorção pode ser tratada como uma alternativa, ou forma de atuação conjunta, nas operações de detoxificação de efluentes industriais e residenciais. Dentre as principais vantagens verificadas pode-se citar: o potencial de descontaminar sistemas com grande volume de efluentes; baixo custo operacional; utilização de resíduos de outros processos; e a capacidade de recuperação de espécies metálicas, caso a biomassa demonstre determinada seletividade. ${ }^{29}$

\section{Complexação}

A complexação está centrada na formação de compostos de coordenação por meio da doação de elétrons para íons metálicos, sendo esse doador de elétrons denominado ligante e responsável por promover uma ligação covalente com cátions metálicos (ou átomos metálicos neutros) baseado na sua disponibilidade no compartilhamento de elétrons. ${ }^{30}$

O número de coordenação nada mais é do que a quantidade de ligações estabelecidas entre o cátion e o ligante, assumindo, tipicamente, os valores 2,4 e 6 , que resultam em compostos que podem ser eletricamente neutros, negativos ou positivos. ${ }^{30}$

Assim, quanto maior for a disponibilidade de doação de elétrons pela biomassa, tanto intra quanto extracelularmente, de forma mais efetiva o processo de complexação se fará presente. Ou seja, sua capacidade de reter íons metálicos por essa via será de interesse de estudo na aplicação de tal biomassa perante a remoção de cátions metálicos do meio. ${ }^{30}$ 


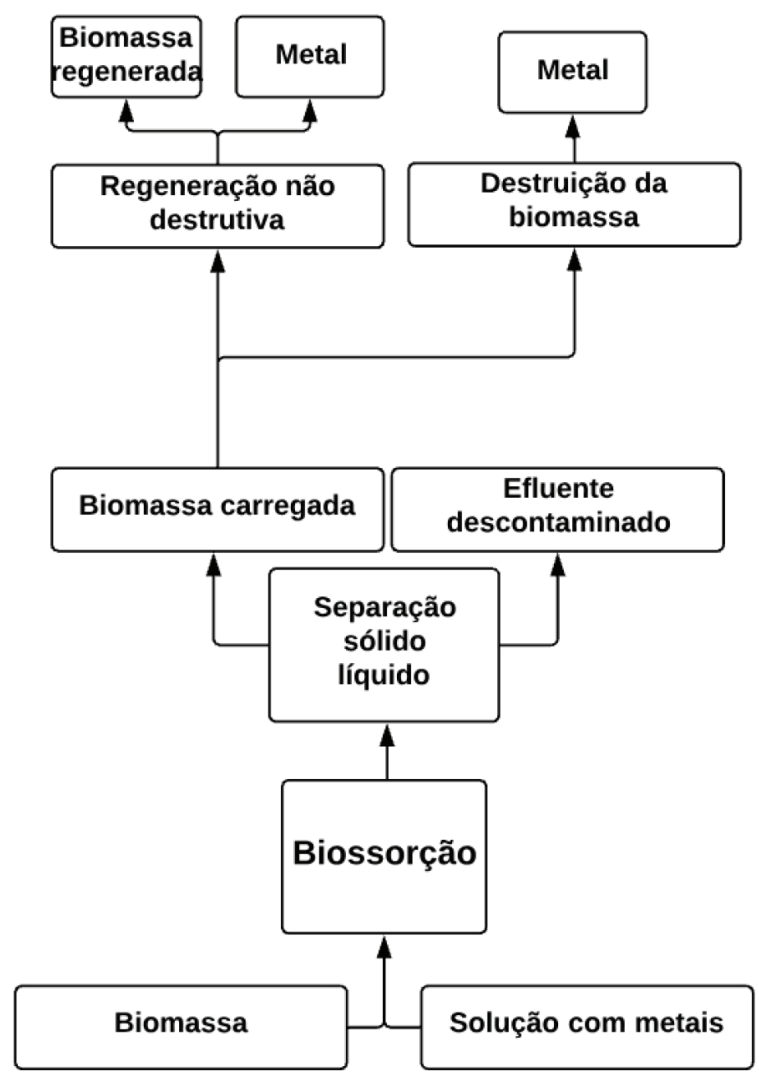

Figura 3. Representação da biossorção de metais por meio da utilização de biomassa. Adaptada da ref. 27

\section{Microprecipitação}

É um processo muito utilizado em testes sorológicos, no qual o antissoro e o antígeno são introduzidos na mesma quantidade e, após agitação, geram precipitados microscópicos que são então analisados por meio de microscopia. ${ }^{31}$

No contexto da biossorção, a microprecipitação se fundamenta na ocorrência de precipitação, em nível microscópico, de compostos na superfície do material biossorvente. Sendo a microprecipitação um mecanismo oriundo da alteração de condições ambientais ao redor da superfície da biomassa (biossorvente), que podem ocasionar, por exemplo, alterações no $\mathrm{pH}$ local e, com isso, gerar a precipitação dos compostos na parte externa da biomassa. ${ }^{27}$

\section{Adsorção}

A adsorção é um processo no qual determinada substância, seja ela gasosa, líquida ou sólida, fica ligada sobre a superfície do material adsorvente sólido. Essa adesão das moléculas pode ocorrer tanto por forças químicas quanto físicas, sendo que a capacidade de adsorção depende de diversos fatores físico-químicos, como área superficial, temperatura, $\mathrm{pH}$, agitação. ${ }^{32}$

Assim, como os componentes adsorvidos ficam dispostos na superfície externa do adsorvente, quanto mais extensa for a superfície externa em relação a unidade de massa sólida, mais favorável será à adsorção. ${ }^{33}$

A temperatura, por sua vez, atua na adsorção principalmente em relação à constante de velocidade de reação, sendo que o aquecimento acentua a energia cinética, a mobilidade dos componentes do adsorvato, bem como a difusão intrapartícula do componente a ser adsorvido. Outro ponto a ser levado em consideração em relação à influência da temperatura é que a elevação da mesma pode promover a desobstrução de poros internos do adsorvente, promovendo o aumento da área superficial e à entrada de moléculas maiores no interior do material. ${ }^{34}$

$\mathrm{O}$ pH irá determinar o grau de distribuição das espécies químicas, sendo a intensidade do efeito diretamente dependente do adsorvente, pois as cargas superficiais variam conforme a composição do material. Assim, o pH será o fator que irá determinar a carga da superfície do material adsorvente, além de ser decisivo entre as interações eletrostáticas entre o adsorvato e o adsorvente. ${ }^{33}$

A agitação poderá, assim como a temperatura, acentuar a mobilidade das espécies de adsorvato, favorecendo o processo de adsorção. ${ }^{35}$

No momento que o adsorvato, um composto presente em solução líquida ou gasosa, entra em contato com o adsorvente, um material sólido, o processo de adsorção irá ocorrer até que o equilíbrio seja estabelecido, ou seja, até que a concentração do adsorvato permaneça constante na solução em que se encontra. Por meio da determinação do ponto em que o equilíbrio é estabelecido, levando em consideração massas diferentes de material adsorvente, é possível construir isotermas de adsorção, como a representada pela Figura $4 .^{33}$

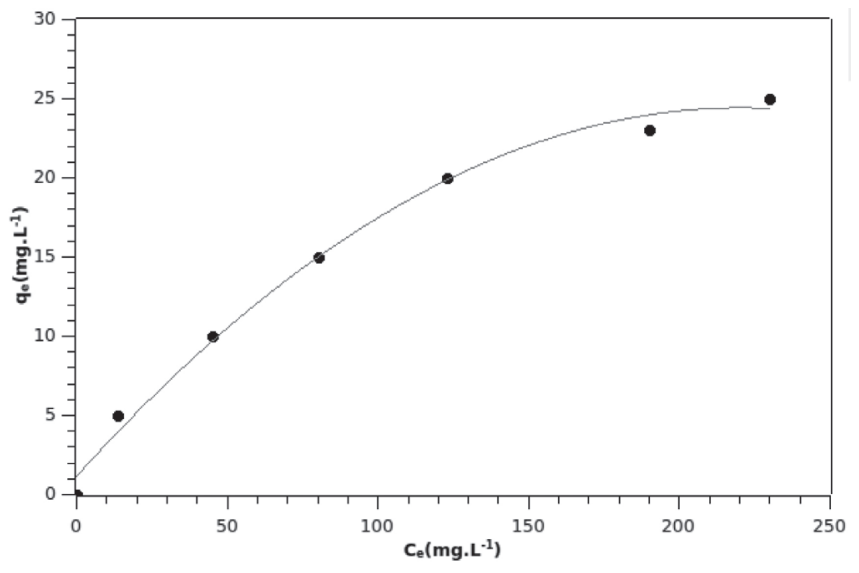

Figura 4. Exemplo de isoterma de adsorção. Adaptada da ref. 33

em que $\mathrm{C}_{\mathrm{e}}$ representa a concentração de adsorvato presente na solução após a adsorção atingir o equilíbrio, e q é referente a capacidade de adsorção do material adsorvente.

Por meio das isotermas é possível obter gráficos variados, que podem ser analisados em função da adsorção ocorrer de forma favorável ou desfavorável, como representado na Figura $5 .{ }^{33}$

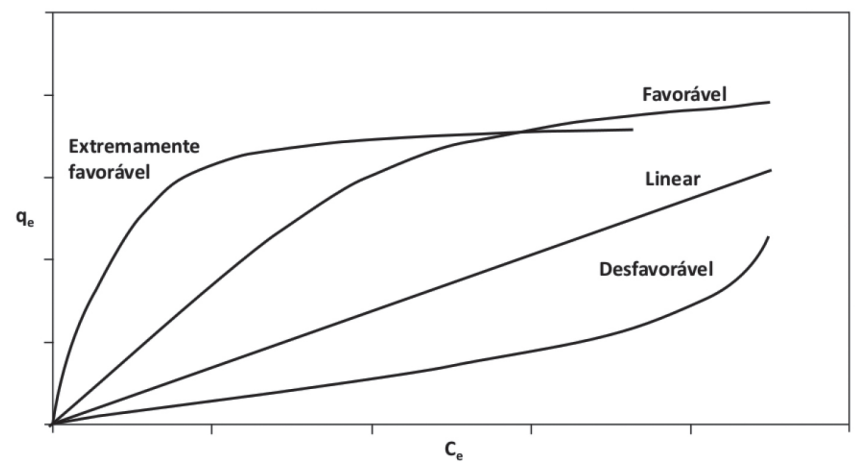

Figura 5. Comportamentos possíveis para isotermas de adsorção ${ }^{33}$

Para estudar o comportamento da adsorção existem modelos matemáticos de isotermas propostos, onde se encontram parâmetros para ajustar os dados obtidos experimentalmente em relação aos valores de $\mathrm{q}_{\mathrm{e}} \mathrm{e}_{\mathrm{e}}$, como o de Langmuir e Freudlich. A teoria na qual 
o modelo de Langmuir é baseado considera que a adsorção ocorre em sítios uniformes, originando apenas uma monocamada na qual a afinidade iônica independe da quantidade de material adsorvido. Já o modelo de Freudlich não aplica essa uniformidade, sendo um dos primeiros modelos a considerar a relação entre a quantidade de compostos adsorvidos e a concentração de compostos presentes na solução de forma empírica. ${ }^{36}$ Dessa forma, este modelo pode ser muito bem aplicado em sistemas que não se comportam de forma ideal, em sistemas de adsorção multicamada e também em superfícies heterogêneas. ${ }^{33}$

\section{Troca Iônica}

É o processo no qual ocorre uma troca de íons presentes numa solução aquosa com uma concentração relativamente reduzida, para outra, de maior concentração, por meio de um material insolúvel (biomassa no contexto da biossorção). Ou seja, íons fracamente ligados na superfície da resina podem ser transferidos por íons presentes na solução, desde que possuam o mesmo sinal. O processo promove uma troca estequiométrica e reversível, ocorrendo até que o equilíbrio seja estabelecido. Por meio de forças eletrostáticas (forças entre partículas promovida pela carga elétrica das mesmas) e da força de van der Waals (somatório das forças atrativas ou repulsivas), os íons ficam ligados em sítios de troca iônica estabelecidos no biossorvente. ${ }^{37}$
A natureza dos íons, como carga, grau de hidratação e tamanho são propriedades que influenciam de forma direta no comportamento da troca iônica, sendo responsáveis pelo número total de íons capazes de sofrerem permutação. ${ }^{38}$

Este processo que é um dos mecanismos que pode estar presente na operação de biossorção utilizando biomassa, é o mesmo já há muito aplicado no tratamento de águas domésticas, no qual íons de sódio presentes em resinas de troca iônica (catiônica) são transferidos para a água, sendo o lugar ocupado então por cálcio e magnésio, fazendo com que a dureza da água diminua. ${ }^{38}$

\section{CAPACIDADE BIORREMEDIATIVA DAS MICROALGAS}

Inúmeras pesquisas estão sendo realizadas com o intuito de determinar possíveis aplicações para a biomassa de microalgas, muitas delas retornando resultados muito promissores, conseguindo agregar valor aos compostos gerados e/ou inserir em processos já existentes. Uma dessas aplicações é na biorremediação, uma vez que, como já descrito anteriormente, a constituição bioquímica das microalgas viabiliza processos de biossorção. A Tabela 5 traz de forma resumida os trabalhos revisados, explicitando as espécies bem como os compostos sobre os quais as mesmas atuaram na remediação e as eficiências alcançadas.

Tabela 5. Potencial de biorremediação de microalgas sobre diversos compostos

\begin{tabular}{|c|c|c|c|}
\hline Espécie & Composto(s) remediado(s) & Remoção (\%) & Referência \\
\hline Chlorella sorokiniana & $\begin{array}{l}\text { Fósforo inorgânico } \\
\text { Nitrogênio amoniacal } \\
\text { Fósforo inorgânico } \\
\text { Nitrogênio amoniacal }\end{array}$ & $\begin{array}{c}84^{[\mathrm{a}]} \\
49^{[\mathrm{a}]} \\
80-88^{[\mathrm{b}]} \\
64-82^{[\mathrm{b}]}\end{array}$ & 39 \\
\hline Phaeodactylum tricornutum & Oxitetraciclina & 97 & 40 \\
\hline Chlorella vulgaris & $\begin{array}{l}\text { Nitratos } \\
\text { Fosfatos }\end{array}$ & $\begin{array}{l}72,40 \\
76,13\end{array}$ & 41 \\
\hline Chlorella sp. & Cádmio & 48,7 & 42 \\
\hline Chlorella sp. & $\begin{array}{l}\text { Dióxido de carbono } \\
\text { Óxido de nitrogênio } \\
\text { Dióxido de enxofre }\end{array}$ & $\begin{array}{l}60 \\
70 \\
50\end{array}$ & 25 \\
\hline $\begin{array}{l}\text { Chlorella vulgaris } \\
\text { Synechocystis salina } \\
\text { Microcystis aeruginosa }\end{array}$ & $\begin{array}{l}\text { Nitrogênio } \\
\text { Fósforo }\end{array}$ & $\begin{array}{l}\cong 100 \\
\cong 100\end{array}$ & 43 \\
\hline Scenedesmus sp. & $\begin{array}{c}\text { Amônia } \\
\text { Nitrato } \\
\text { Fosfato } \\
\text { Oxigênio químico }\end{array}$ & $70-98$ & 44 \\
\hline Scenedesmus obliquus & $\begin{array}{l}\text { Amônia } \\
\text { Fosfato }\end{array}$ & $\begin{array}{l}>97 \\
>97\end{array}$ & 45 \\
\hline $\begin{array}{l}\text { Chlamydomonas biconvexa } \\
\text { Tetranephris sp. }\end{array}$ & $\begin{array}{l}\text { Nitrogênio } \\
\text { Fósforo }\end{array}$ & $\begin{array}{l}\geq 60 \\
\geq 90\end{array}$ & 46 \\
\hline Chlorella vulgaris & $\begin{array}{l}\text { Nitrogênio } \\
\text { Fósforo } \\
\text { Zinco }\end{array}$ & $\begin{array}{l}90,6 \\
98,7 \\
85,4 \\
\end{array}$ & 47 \\
\hline Spirulina platensis & $\begin{array}{l}\text { Cobre } \\
\text { Zinco }\end{array}$ & $\begin{array}{l}99 \\
95 \\
\end{array}$ & 48 \\
\hline Spirulina platensis & Cromo (VI) & 62 & 49 \\
\hline Chlorella vulgaris & $\begin{array}{l}\text { Amônia } \\
\text { Fósforo } \\
\text { Ferro } \\
\text { Manganês } \\
\text { Cobre } \\
\text { Zinco }\end{array}$ & $\begin{array}{l}82,2 \\
51,9 \\
88,2 \\
79,5 \\
58,2 \\
60,9\end{array}$ & 50 \\
\hline
\end{tabular}

${ }^{\mathrm{a} S e m}$ aplicação de $\mathrm{CO}_{2}{ }^{\mathrm{b}} \mathrm{Com}$ aplicação de $\mathrm{CO}_{2}$. 


\section{Biorremediação de macro e micronutrientes}

Utilizando um reator UASB com e sem aplicação de $\mathrm{CO}_{2}$, Slompo $^{39}$ testou o potencial de recuperação de nutrientes de água negra por meio da utilização da microalga Chlorella sorokiniana. No ensaio sem aplicação de $\mathrm{CO}_{2}$, a remoção de fósforo inorgânico atingiu $84 \%$, além de remover $49 \%$ de nitrogênio amoniacal. Já com a utilização de $\mathrm{CO}_{2}$ foram visualizadas remoções maiores, entre 80 a $88 \%$ para o nitrogênio amoniacal e 64 a 82\% para o fósforo inorgânico.

Por meio da utilização da Chlorella vulgaris imobilizada em matriz de gel de alginato de sódio e aplicada na comparação entre a biorremediação de água natural e água residual, efetivado por Pimenta, ${ }^{41}$ avaliando a concentração de amônia, nitratos e fosfatos, o autor obteve resultados expressivos de remoção de nitratos e fosfatos (72,40\% e 76,13\%, respectivamente) presentes em água residual, enquanto a remoção de amônia atingiu 40,22\% em água natural e apenas $2,71 \%$ em água residual.

Também utilizando Chlorella sp., Chiu et al. ${ }^{25}$ avaliaram o potencial da espécie na remoção de dióxido de carbono $\left(\mathrm{CO}_{2}\right)$, óxido de nitrogênio (NO) e dióxido de enxofre $\left(\mathrm{SO}_{2}\right)$ oriundos de gás de combustão gerado a partir de um forno de coque. Nesse trabalho, as microalgas, inseridas em um fotobiorreator externo, obtiveram uma eficiência de remoção de $60 \%$ para o $\mathrm{CO}_{2}, 70 \%$ para o $\mathrm{NO}$ e $50 \%$ para o $\mathrm{SO}_{2}$.

Gonçalves et al. ${ }^{43}$ testaram o efeito do aumento das concentrações de $\mathrm{CO}_{2}$ em relação a captura do mesmo, produção de biomassa e biorremediação de águas residuais. Para tanto, fizeram uso de cianobactérias (Synechocystis salina e Microcystis aeruginosa) e microalgas (Chlorella vulgaris e Pseudokirchneriella subcapitata), variando as concentrações de $\mathrm{CO}_{2}$ entre 0,004 e $10 \%$ v/v. C. vulgaris, $S$. salina e $M$. aeruginosa apresentaram as maiores produtividades de biomassa $\left(0,126 \pm 0,033 \mathrm{gdw} \mathrm{L} \mathrm{L}^{-1} \cdot \mathrm{d}^{-1}\right)$, obtendo $0,101 \pm 0,027 \mathrm{gC} \mathrm{L}^{-1} \mathrm{~d}^{-1}$ para taxa de fixação de carbono. A avaliação do potencial biorremediador focou nos nutrientes nitrogênio e fósforo, cujas porcentagens de remoção, em relação aos mesmo microrganismos, ficaram próximas de $100 \%$.

Em estudo semelhante ao anterior, Nayak et al. ${ }^{44}$ avaliaram o desempenho de microalgas na remediação de águas residuárias domésticas (testando amônia, nitrato, fosfato e oxigênio químico), em biofixar $\mathrm{CO}_{2}$ e também promover a biossíntese de lipídios com o intuito de aplicar o mesmo na produção de biodiesel. Inicialmente, os autores testaram várias espécies de microalgas em um fotobiorreator, obtendo os melhores resultados para Scenedesmus sp., que retornou uma taxa de crescimento específico máximo de $0,44 \mathrm{~d}^{-1}$, rendimento em biomassa de $0,43 \mathrm{~g} \mathrm{~L}^{-1}$, teor lipídico total de $23,1 \%$ e produtividade de biomassa de $61,4 \mathrm{mg} \mathrm{L}^{-1} \mathrm{~d}^{-1}$. Após, os autores variaram as concentrações de $\mathrm{CO}_{2}$ inseridas no fotobiorreator, constatando que a cultura de microalga suplementada com 2,5\%(v/v) foi a que mais se adequou ao sistema, sendo que a taxa de consumo de $\mathrm{CO}_{2}$ foi de $368 \mathrm{mg} \mathrm{L}^{-1} \mathrm{~d}^{-1}$, a produtividade de biomassa foi de $196 \mathrm{mg} \mathrm{L}^{-1} \mathrm{~d}^{-1}$, o conteúdo lipídico total $33,3 \%$ e a produtividade lipídica $65,17 \mathrm{mg} \mathrm{L}^{-1} \mathrm{~d}^{-1}$. Em relação ao potencial biorremediador, a microalga promoveu uma remoção entre 70-98\% para os compostos testados (amônia, nitrato, fosfato e oxigênio químico).

Também utilizando microalgas do gênero Scenedesmus, Oliveira et al..$^{45}$ estudaram o potencial de $S$. obliquus na biorremediação de águas residuárias da indústria avícola. Os resultados obtidos demonstraram que, para um período de 13 dias, a eficiência de remoção foi superior a $97 \%$ tanto para amônia quanto para fosfato.

Nascimento $^{46}$ cultivou microalgas Chlamydomonas biconvexa e Tetranephris sp. em fotobiorreatores air lift de placas planas com suplementação de $\mathrm{CO}_{2}$ em meio composto por efluente de lagoa de estabilização de palm oil mill efluent (POME), com intuito de verificar a capacidade de tais microrganismos em removerem nitrogênio e fósforo. Os resultados demonstraram uma considerável remoção dos dois componentes, que atingiu $\geq 60 \%$ para o nitrogênio e $\geq 90 \%$ para o fósforo, que ocorreu principalmente durante a fase exponencial de crescimento das microalgas. Dessa forma, o efluente oriundo da lagoa de estabilização de POME pode ser biorremediado pelas duas cepas testadas, entretanto, os melhores resultados foram obtidos com a cepa de Tetranephris $s p$.

Com o foco de testar o poder de remoção de metais pesados e de nutrientes (fósforo e nitrogênio), presentes em soluções sintéticas contendo os metais pesados cádmio $(\mathrm{Cd})$ níquel $(\mathrm{Ni})$ e zinco $(\mathrm{Zn})$, além de combinações entre os mesmos, Dos $\operatorname{Santos}^{47}$ utilizou a microalga Chlorella vulgaris e variou as concentrações dos metais entre $1 \mathrm{e}$ $3 \mathrm{mg} \mathrm{L}^{-1}$. No controle, sem a presença de qualquer metal, foi constatado um padrão de crescimento máximo de $0,934 \mathrm{~d}^{-1}$, na presença de Cd (1 mg L $\left.{ }^{-1}\right)$ e também na de $\mathrm{Zn}\left(1 \mathrm{mg} \mathrm{L}^{-1}\right)$ o valor máximo obtido foi de $0,34 \mathrm{~d}^{-1}$. As culturas que cresceram em meio contendo níquel foram as que mais sofreram inibição de seu crescimento, inibição essa que atingiu valores de $>88 \%$ para um concentração de $1 \mathrm{mg} \mathrm{L}^{-1}$ de Ni. As culturas com cádmio na concentração de $1 \mathrm{mg} \mathrm{L}^{-1}$ promoveram a maior produtividade algal, além das maiores remoções de nitrogênio $(90,6 \%)$ e fósforo $(98,7 \%)$. Focando apenas na diminuição da concentração de metais pesados, os melhores resultados foram obtidos nas culturas de zinco $1 \mathrm{mg} \mathrm{L}^{-1}$, em que a remoção do mesmo atingiu o valor de $85,4 \%$.

Também testando a eficácia na remoção de cobre e zinco, Reck et al. ${ }^{48}$ utilizaram a cepa de Spirulina platensis que estava sendo aplicada na biorremediação de efluente piscícola de Oreochromis niloticus (tilápia-donilo). Para avaliação da capacidade de remoção dos metais, foram aplicadas soluções sintéticas obtidas a partir de $\mathrm{CuSO}_{4}$, para estudo do cobre, e $\mathrm{ZnSO}_{4}$ para estudo do zinco, sendo ambas as soluções preparadas com concentração de $100 \mathrm{mg} \mathrm{L}^{-1}$. Os autores testaram em diferentes condições de $\mathrm{pH}$, concentração do biossorvente (biomassa inativa) e agitação. Os ensaios apresentaram remoções de $99 \%$ para o cobre e $95 \%$ para o zinco, sendo que o único parâmetro de influência significativa foi a variação do biossorvente.

Silva et al. ${ }^{50}$ utilizaram efluente oriundo do cultivo de hortaliças por hidroponia, rico em fósforo e nitrogênio, para promover o crescimento de Chlorella vulgaris e avaliar a biorremoção desses nutrientes e dos metais ferro, manganês, cobre e zinco inseridos a partir de soluções sintéticas. A remoção de amônia atingiu $82,2 \%$, de fósforo total a remoção foi de $51,9 \%, 88,22 \%$ para o ferro, $79,54 \%$ para o manganês, $58,2 \%$ para o cobre e $60,91 \%$ para o zinco. Tais valores possibilitaram que a conclusão de outros pesquisadores fosse corroborada, uma vez que é quantitativamente visível o potencial positivo de fico biorremediação através da Chlorella vulgaris.

Ottonelli ${ }^{51}$ fomentou a avaliação do potencial de biorremediação de metais pela microalga Pseudokirchneriella subcapitata. A autora testou cinco tipos de tratamentos: o primeiro, sendo o controle, contendo água destilada autoclavada, meio NPK e a microalga; o segundo com a composição do controle mais cloreto de alumínio; o terceiro com a composição do controle mais sulfato ferroso; o quarto com a composição do controle mais sulfato de zinco; e o quinto contendo o controle mais cloreto de alumínio + sulfato ferroso + sulfato de zinco. Nesses ensaios foi constatada uma elevada capacidade de remoção dos metais das soluções sintéticas, pois tanto o ferro, quanto alumínio, zinco e sais de nitrogênio e fósforo retornaram medidas reduzidas no meio de cultivo filtrado, comprovando o potencial biorremediador de tal microalga frente tais compostos.

\section{Biorremediação de oxitetraciclina}

Santaeufemia et al..$^{40}$ utilizaram Phaeodactylum tricornutum na biorremediação de oxitetraciclina em água do mar por meio de 
biomassa ativa e inativa. Foi constatado que a biomassa ativa retornou maior eficiência quando comparada com a biomassa inativa, atingindo 29,18 $\mathrm{mg} \mathrm{g}^{-1}$ de capacidade máxima de adsorção, enquanto a biomassa inativa apresentou 4,54 $\mathrm{mg} \mathrm{g}^{-1}$ de competência adsortiva. Avaliando uma concentração inicial de $2,5 \mathrm{mg} \mathrm{L}^{-1}$ de oxitetraciclina, $97 \%$ do composto foi removido, sendo a influência da biorremediação mais incisiva do que a fotodegradação, demonstrando enorme potencial de remoção com baixo custo do antibiótico da água do mar.

\section{Biorremediação de metais pesados (Cd e $\mathrm{Cr}(\mathrm{VI}))$}

O trabalho de Matsunaga et al., ${ }^{42}$ envolvendo a triagem de microalgas marinhas com o intuito de aplicação das mesmas na remoção de cádmio $(\mathrm{Cd})$ presente em água salgada contaminada, obteve 24 cepas com capacidade de biorremediação do metal pesado, sendo 19 algas verdes e 5 cianobactérias capazes de reterem mais de $10 \%$ do total de $\mathrm{Cd}$ inicialmente medido no meio. Uma das cepas, a alga marinha Chlorella sp., foi a mais efetiva, promovendo uma remoção de $48,7 \%$ do total de $\mathrm{Cd}$. Além de avaliar o potencial biorremediador, os autores ainda constataram que $67 \%$ do Cd removido foi acumulado intracelularmente, enquanto $25 \%$ sofreu adsorção superficial nos organismos testados.

Utilizando Spirulina platensis, Dal Magro ${ }^{49}$ realizou ensaios de biossorção passiva de cromo (VI). O parâmetro de maior influência foi o $\mathrm{pH}$, onde com o valor de $\mathrm{pH}$ igual a 3 a biossorção promoveu uma remoção de $61,97 \%$ de cromo (VI) presente na solução. Os índices mais elevados de remoção foram verificados durante os primeiros 10 minutos de ensaio, e a capacidade adsortiva obtida pela biomassa inativa de Spirulina platensis atingiu 100,39 mg de cromo (VI) por grama de biomassa.

\section{CONSIDERAÇÕES FINAIS}

A presente revisão levantou estudos que abordaram uma gama diversa de espécies de microalgas em relação ao potencial de atuação na biorremediação de diversos compostos. A capacidade remediativa, tanto de nutrientes quanto de metais pesados, foi constatada por inúmeros estudos, sendo uma forma barata e muitas vezes mais eficiente quando comparada aos métodos tradicionais de remediação.

$\mathrm{O}$ fato de existirem inúmeras espécies de microalgas, que podem ocupar faixas diversas de $\mathrm{pH}$, temperatura, $\mathrm{CO}_{2}$ dissolvido, etc, serve como estímulo para que mais pesquisas nessa área sejam concretizadas. Além do foco na remoção de compostos poluentes presentes nos mais diversos efluentes, é possível almejar a produção de compostos a partir da biomassa gerada na biorremediação, o que pode tornar produção de compostos de valor agregado largamente biosustentavel.

\section{REFERÊNCIAS}

1. Rocha, O. D.; Nascimento, G. D.; Campos, N. F.; Silva, V. D.; Duarte, M. M. M. B.; Quim. Nova 2012, 35, 1369.

2. De Freitas Muniz, D. H.; Oliveira-Filho, E. C.; Universitas: ciências da saúde 2008, 4, 83.

3. De Aguiar, M. R. M. P.; Novaes, A. C.; Guarino, A. W. S.; Quim. Nova 2002, 25, 1145 .

4. BRASIL. Resolução n. ${ }^{\circ} 430$, de 13 de maio de 2011. Dispõe sobre as condições e padrões de lançamento de efluentes, complementa e altera a Resolução n. ${ }^{\circ}$ 357, de 17 de março de 2005, do Conselho Nacional do Meio Ambiente-CONAMA. Diário Oficial da União, 2011.

5. Pinhati, F. R.; Del Aguila, E. M.; Tôrres, A. P. R.; de Sousa, M. P.; Santiago, V. M. J.; Silva, J. T.; Paschoalin, V. M. F.; Quim. Nova 2014, 37,1269
6. Borges, T. N.; Costa, R. M.; Gontijo, H. M.; Research, Society and Development, 2019, 8, e5081742.

7. Valente, J. P. S.; Padilha, P. M.; da Silva, A. M. M.; Eclet. Quim. 2018, 22, 2018.

8. Botero, W. G.; Souza, S. O.; Santos O. S.; Quim. Nova 2014, 37, 943.

9. Franco, A. L. C.; Lôbo, I. P.; Cruz, R. S.; Teixeira, C. M. L. L.; Almeida Neto, J. A. D.; Menezes, R. S.; Quim. Nova 2013, 36, 437.

10. Bertoldi, F. C.; Sant'anna, E. R. N. A. N. I.; Oliveira, J. L. B.; Bol. Cent. Pesqui. Process. Aliment. 2008, 26, 9.

11. Schimtz, R.; Dal Magro, C.; Colla, L. M.; Revista CIATEC-UPF 2012 , 4,48 .

12. Ortenzio, Y. T.; Amaral, G. G.; dos Santos Almeida, S.; de Oliveira, E. C. A. M.; Bioenergia em Revista: Diálogos 2015, 5, 1.

13. Defanti, L. S.; Siqueira, N. S.; Linhares, P. C.; Revista de Divulgação do Projeto Universidade Petrobras e Instituto Federal Fluminense 2010, 1 , 11.

14. Feroldi, M.; Cremonez, P. A.; Estevam, A.; Revista Monografias Ambientais 2014, 13, 3800.

15. Huang, G.; Chen, F.; Wei, D.; Zhang, X.; Chen, G.; Appl. Energy 2010, 87,38 .

16. Mota, C. J.; Monteiro, R. S.; Quim. Nova 2013, 36, 1483.

17. Rodrigues, J. B. R.; Belli Filho, P.; Biotemas 2004, 17, 7.

18. Pereira, C. M.; Hobuss, C. B.; Maciel, J. V.; Ferreira, L. R.; Del Pino, F. B.; Mesko, M. F.; Colepicolo Neto, P.; Quim. Nova 2012, 35, 2013.

19. Defanti, L. S.; Siqueira, N. S.; Linhares, P. C.; Revista de divulgação do Projeto Universidade Petrobras e IF Fluminense 2010, 1, 11.

20. Suarez, P. A.; Santos, A. L.; Rodrigues, J. P.; Alves, M. B.; Quim. Nova 2009, 32, 768.

21. Gris, L. R. S.; Dissertação de Mestrado, Universidade Federal do Rio Grande do Sul, Brasil, 2011.

22. Mata, T. M.; Martins, A. A.; Caetano, N. S.; Renewable Sustainable Energy Rev. 2010, 14, 217.

23. Moreira, D. R.; Dissertação de Mestrado, Pontifícia Universidade Católica do Rio Grande do Sul, Brasil, 2010.

24. Mimura, A. M. S.; Vieira, T. D. A.; Martelli, P. B.; Gorgulho, H. D. F.; Quim. Nova 2010, 33, 1279.

25. Chiu, S. Y.; Kao, C. Y.; Huang, T. T.; Lin, C. J.; Ong, S. C.; Chen, C. D.; Lin, C. S.; Bioresour. Technol. 2011, 102, 9135.

26. Pino, G. A. H.; Dissertação de mestrado, Pontifícia Universidade Católica do Rio de Janeiro, Brasil, 2005.

27. Boniolo, M. R.; Tese de Doutorado, Universidade de São Paulo, Brasil, 2008.

28. Da Silva, K. M. D.; Rezende, L. C. S. H.; Bergamasco, R.; da Silva, C. A.; Silva Gonçalves, D.; Engevista 2012, 15, 43.

29. Pino, G. H.; Torem, M. L.; Tecnol. Metal., Mater. Min. 2011, 8, 57.

30. Atkins, P.; Overton, Tina.; Rourke, J.; Weller, M.; Armstrong, F.; Inorganic Chemistry, $5^{\text {a }}$ ed., Oxford University Press: Oxford, 2009.

31. Henning, A. A.; Patologia de sementes, Embrapa Soja-Documentos (INFOTECA-E), 1994.

32. Penha, F. G.; Spier, V. C.; Debacher, N. A.; Quim. Nova 2001, 24, 612.

33. Do Nascimento, R. F.; Lima, A. C. A.; Vidal, C. B.; Melo, D. Q.; Raulino, G. S. C.; Biblioteca de Ciências e Tecnologia, 2014.

34. Araujo, A. L. P.; Silva, M. C. C.; Gimenes, M. L.; Barros, M. A. S. D.; Scientia Plena 2009, 5, 12.

35. Vicari Mellis, E.; Rodella, A. A.; Bragantia 2008, 67, 1.

36. Sodré, F. F.; Lenzi, E.; Costa, A. D.; Quim. Nova 2001, 24, 324.

37. Borba, C. E.; Tese de Doutorado, Universidade Estadual de Campinas, Brasil, 2009.

38. de Oliveira, M. M.; Dissertação de Mestrado, Universidade Federal da Paraíba, Brasil, 2008.

39. Slompo, L.; Dissertação de Mestrado, Universidade Estadual Paulista, Brasil, 2018. 
40. Santaeufemia, S.; Torres, E.; Mera, R.; Abalde, J.; J. Hazard. Mater 2016, 320, 315.

41. Pimenta, S. F. P.; Dissertação de Mestrado, Universidade do Porto, Portugal, 2012.

42. Matsunaga, T.; Takeyama, H.; Nakao, T.; Yamazawa, A.; J. Biotechnol. 1999, 70, 33.

43. Gonçalves, A. L.; Rodrigues, C. M.; Pires, J. C.; Simões, M.; Algal Res. 2016, 14, 127.

44. Nayak, M.; Karemore, A.; Sen, R.; Algal Res. 2016, 16, 216.

45. Oliveira, A. C.; Barata, A.; Batista, A. P.; Gouveia, L.; Environ. Technol. (2018), DOI: 10.1080/09593330.2018.1488003.

46. do Nascimento, R. C.; Dissertação de Mestrado, Universidade Federal do Tocantins, Brasil, 2016.
47. dos Santos, F. M. L. F.; Dissertação de Mestrado, Universidade do Porto, Portugal, 2017.

48. Reck, L.; Abreu, K. V.; Davi, D. M. B.; Magalhães, C. E. C.; Alves, C. R.; Pires-Cavalcanti, K. M. S.; $12^{\circ}$ Encontro Brasileiro sobre Adsroção, Gramado, Brasil, 2018.

49. Dal Magro, C.; Deon, M. C.; Thomé, A.; Piccin, J. S.; Colla, L. M.; Quim. Nova 2013, 36, 1139.

50. da Silva, F.; Dissertação de Mestrado, Universidade Federal de Santa Catarina, Brasil, 2006.

51. Ottonelli, F.; Trabalho de conclusão de curso, Universidade Federal da Grande Dourados, Brasil, 2013. 